\title{
MELHORAMENTO DO TRIGO. XII. COMPORTAMENTO DE NOVAS LINHAGENS E CULTIVARES NO ESTADO DE SÃO PAULO $\left({ }^{1}\right)$
}

\author{
CARLOS EDUARDO DE OLIVEIRA CAMARGO $\left({ }^{2,6}\right)$, JOĀO CARLOS \\ FELICIO $\left({ }^{2,6}\right)$, JOSE GUILHERME DE FREITAS $\left({ }^{2,6}\right)$, BENEDITO DE \\ CAMARGO BARROS $\left({ }^{3,6}\right.$ ), JAIRO LOPES DE CASTRO ${ }^{4,6}$ ) \\ Q JOSÉ CARLOS SABINO ( $\left.{ }^{5}\right)$
}

\begin{abstract}
RESUMO
Foram comparadas entre si vinte e uma linhagens e quatro cultivares comerciais de trigo através de ensaios instalados em diferentes localidades paulistas, analisando-se os seguintes parâmetros: rendimento de grăos, altura de plantas, ciclo em dias da emergência ao florescimento e da emergência à maturação, porcentagem de plantas acamadas, comprimento da espiga, número de grãos por espiga e por espigueta, número de espiguetas por espiga, peso de cem grãos, resistência à ferrugem-

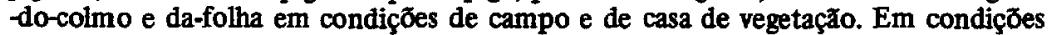
de laboratório, foram realizados estudos da tolerância ao alumínio, em soluç̧es nutritivas. Nos ensaios conduzidos em Campinas, em condiçăo de irrigação por aspersão, destacaram-se, quanto à produçäa de grãos, as linhagens IAC-60 e IAC-67, e, nos de Capăo Bonito, IAC-66, IAC-60 e IAC-69 apresentaram maior produtividade. As linha-
\end{abstract}

${ }^{1}$ ) Trabatho apresentado na XIII Reuniāo Nacional de Pesquisa de Trigo, Cruz Alta (RS), 1984. Com verba suplementar do Acordo do Trigo entre as Cooperativas de Produtores Rurais do Vale do Paranapanema e a Secretaria de Agricultura è Abastecimento, através do Instituto Agronômico. Os autores agradecem ao Centro Nacional de Pesquisa de Trigo (EMBRAPA) os testes de resistência às ferrugens do colmo e da folha em casa de vegetação. Recebido para publicação em 13 de setembro de 1984.

(2) Seçāo de Arroz e Cereais de Inverno, Instituto Agronômico (IAC), Caixa Postal 28, 13100 Campinas, SP.

(3) Seção de Doenças das Plantas Alimentícias Básicas e Olerícolas, Instituto Biológico.

(4) Estaçăo Experimental de Capão Bonito, IAC.

$\left({ }_{6}^{5}\right)$ Estação Experimental de Tietê, IAC.

(6) Com bolsa de suplementação do CNPq. 
gens IAC-64,IAC-68, IAC-71 e IAC-60 destacaram-se em Tietê, e as linhagens IAC-67, IAC-63 e IAC-64 evidenciaram alta produção de grãos em Maracaí. As linhagens IAC-52, IAC-53, IAC-54, IAC-55, IAC-56, IAC-57, IAC-58, IAC-60, IAC-64, IAC-65, IAC-67, IAC-71 e o 'Alondra-S-46' mostraram plantas de porte semi-anão, diferindo significativamente do 'BH-1146', de porte alto. Em relação à ferrugem-do-colmo (Puccinia graminis f. sp. tritici), as linhagens IAC-62 e IAC-65 e o cultivar Alondra-S-46 foram resistentes às sete raças testadas em estádio de plântula em casa de vegetação e também em condições de campo. Em casa de vegetação, a linhagem IAC-64 foi resistente a quatro raças de $P$.'recondita, agente da ferrugem-da-folha, e IAC-52 e IAC-55, a três raças desse patógeno. Em condição de infecção natural no estádio de planta adulta, as linhagens IAC-51, IAC-56, IAC-61, IAC-62, IAC-63 e IAC-67 apresentaram menor grau de infecção dessa ferrugem, enquanto IAC-51, IAC-60, IAC-63, IAC-68 e IAC-70, bem como 'BH-1146' e 'IAC-18', foram tolerantes à presença de $10 \mathrm{mg} /$ litro de $\mathrm{Al}^{3+}$ na solução nutritiva:

Termos de indexação: trigo; cultivares; linhagens; produção de grāos, altura das plantas; ferrugem do colmo; ferrugem da folha; tolerância, toxicidade de alumínio.

\section{INTRODUÇÃO}

O aumento da produção de trigo no México foi alcançado pelo trabalho conjunto dos cientistas da Fundação Rockefeller e dos próprios mexicanos. Em 1943, quando o programa foi iniciado, o México importava a metade do trigo necessário à sua demanda. Com um programa de melhoramento genético liberando gradativamente cultivares mais produtivos e com um maior conhecimento das técnicas de cultivo do trigo utilizando irrigação e altos níveis de adubação nitrogenada, o México, em 1956, tornou-se autosuficiente e, em 1965, exportador do cereal. As produções por área aumentaram grandemente, tornando sua triticultura altamente rentável (BRIGGS \& KNOWLES, 1977).

O sucesso do cruzamento entre os cultivares Norin 10 e Brevor 14 se deve à grande contribuição prestada à Revolução Verde na Ásia, sendo a base para seleções de linhas semi-anãs nas regiôes tritícolas de todo o mundo (ATHAL, 1971). ALLAN (1970), HEYNE \& CAMPBELL (1971), JOPPA (1973) e CAMARGO \& OLIVEIRA (1981) relataram que altura das plantas e produção de grãos foram correlacioniadas positivamente nos trigos semianões e que os cultivares semi-anões mais altos tiveram as maiores produções.

Por ocasião de alta incidência de ferrugem-do-colmo causada pelo fungo Puccinia graminis f. sp. tritici, ocorre grande redução no rendimento de grãos de trigo. Mesmo com os métodos de controle químico experimentados até o momento, os dados não evidenciaram eficácia que permita descurar a necessidade da resistência genética. A incorporação de resistência à ferrugem-da-folha causada pelo fungo Puccinia recondita assume maior importância no Estado de São Paulo, onde o clima mais seco, no ciclo da cultura, torna menores os prejuízos decorrentes de septorioses, giberela e outros proble- 
mas favorecidos pela conđição excessivamente úmida do extremo Sul do País (OSÓRIO, 1982).

Novas raças dos agentes das ferrugens podem ocorrer por recombinação genética nos patógenos, tomando ineficientes os genes até então utilizados para resistência nas plantas. Também a mudança de prevalência de raças é fator que leva à substituição de cultivares.

A toxicidade de alumínio, encontrada na maioria dos solos e subsolos das regiōes tritícolas do Estado de Săo Paulo, tem dificultado o plantio de cultivares mexicanos de alto potencial produtivo, porém de grande sensibilidade ao $\mathrm{Al}^{3+}$ (CAMARGO \& OLIVEIRA, 1981). A aplicação de calcário, muitas vezes, provoca a precipitação do alumínio das camadas superiores do solo, o qual permanece, no entanto, no subsolo. Como o efeito da toxicidade de alumínio nas plantas, em especial no trigo, consiste na paralisação do crescimento das raízes, torna-se de grande importância o desenvolvimento de cultivares tolerantes.

O presente trabalho teve por objetivo avaliar 21 linhagens de trigo, recém-obtidas do programa de melhoramento genético, juntamente com quatro cultivares atualmente comerciais, em diferentes condições de plantio quanto à produção de grãos, componentes de produção, resistência às doenças e tolerância à toxicidade de $\mathrm{Al}^{3+}$, visando à escolha das mais promissoras para multiplicação e posterior lançamento aos triticultores, ou reutilizá-las no programa de cruzamentos para corrigir possiveis defeitos.

\section{MATERIAL E MÉTODOS}

\subsection{Origem das linhagens e cultivares estudados}

As linhagens estudadas são oriundas de progênies selecionadas resultantes de cruzamentos e/ou retrocruzamentos realizados no Instituto Agronômico, envolvendo linhagens e cultivares de diversas procedências. A relação e a origem das linhagens de trigo estudadas são as seguintes:

IAC-51, IAC-52, IAC-53, IAC-54, IAC-55, IAC-56, IAC-57, IAC-58, IAC-59, IAC-60 e IAC-61 - Selecionadas a partir do híbrido 1196, obtido do cruzamento entre o cultivar IAC-5 e a linhagem IRN-33-70, oriunda do Ensaio Internacional de Ferrugem do Trigo (International Spring Wheat Rust Nursery, IRN), de 1970, conduzido pelo Instituto Biológico.

IAC-62 - Obtida por seleção do híbrido 1644, resultante do cruzamento entre os cultivares JAC- 2 e Sonora-63, este último procedente do Centro Internacional de Milho e Trigo (CIMMYT), México. 
IAC-63 - Oriunda da seleção do híbrido $F_{1}$ 1740, originário do cruzamento entre uma linhagem desconhecida incluida no IRN de 1974 com o cultivar BH-1146.

IAC-64 - Selecionada a partir do híbrido 1050, proveniente do cruzamento 'Paraguay-214' x 'BH-1146', híbrido esse que foi cruzado com a linhagem IRN-33-70.

IAC-65 e IAC-66 - Oriundas de seleçðes do híbrido $F_{1}$ 1235, originárias do cruzamento entre o cultivar Super $x$ e à linhagem IRN-471-63, seguido de quatro retrocruzamentos para a linhagem IRN-471-63.

IAC-67 - Selecionada a partir do híbrido 1645, proveniente do cruzamento entre a linhagem IBN-157-72, originária do Ensaio Internacional de Variedades de Trigo Panificáveis (International Bread Wheat Yield Nursery, IBN) e introduzido do CIMMYT, México, em 1972, com o cultivar IAC-5.

IAC-68 e IAC-69 - Obtidas por seleções do cruzamento entre a linhagem IRN-641-70 e o cultivar BH-1146.

IAC-70 - Oriunda de seleçōes do híbrido 1032, obtido pelo cruzamento entre a linhagem Pel 10054-65, introduzida do Instituto de Pesquisa e Experimentação Agropecuária do Sul (IPEAS), Pelotas, e a IRN-299-66.

IAC-71 - Selecionada a partir do híbrido 1034, proveniente do cruzamento entre a linhagem IRN-641-70 e o híbrido entre as linhagens P 29256, selecionada na Estação Experimental de Capão Bonito, e IRN-102-64.

Como controles, foram utilizados os seguintes cultivares: BH-1 146 e IAC-18, de porte alto, suscetíveis ao agente causal da ferrugem-do-colmo, ciclo precoce e tolerantes à toxicidade de $\mathrm{Al}^{3+}$; IAC-17, de porte alto, moderadamente sensîvel à ferrugem-do-colmo, ciclo precoce e com tolerância intermediária à toxicidade de $\mathrm{Al}^{3+}$, e Alondra-S-46 com porte semi-anão, resistente à ferrugem-do-colmo, ciclo médio a tardio e moderadamente sensível à toxicidade de $\mathrm{Al}^{3+}$. A origem dos cultivares utilizados como controle é a seguinte:

'BH-1 146' - Selecionado no Instituto Agronômico de Minas Gerais, Belo Horizonte, e proveniente do cruzamento 'Ponta Grossa I' x 'Fronteira', híbrido este que foi cruzado com o cultivar Mentana.

'IAC-18' - Oriundo da seleção do híbrido $F_{1} 411$, resultante do cruzamento entre os cultivares BH-1 146 e S-12, este último proveniente da Secretaria da Agricultura do Rio Grande do Sul, seguido de três retrocruzamentos para o 'BH-1 146'.

'IAC-17' - Obtido por seleção a partir do híbrido $F_{1} 75$, resultante do cruzamento entre os cultivares IAS-20 (originário do Rio Grande do Sul) e IRN-526-63 (mexicano). 
'Alondra-S-46' - Selecionado pelo CIMMYT, México, e introduzido pelo Centro Nacional de Pesquisa de Trigo, EMBRAPA, onde foi resselecionado.

\subsection{Ensaios conduzidos em diferentes locais do Estado de São Paulo}

Foi utilizado o delineamento estatístico de blocos ao acaso, com três repetições por local Cada ensaio foi constituído de 75 parcelas, cada uma formada de cinco linhas de $3 \mathrm{~m}$ de comprimento, espaçadas de $0,20 \mathrm{~m}$. Deixou-se uma separação lateral de $0,60 \mathrm{~m}$ entre as parcelas. A semeadura foi feita na base de 80 sementes viáveis por metro de sulco, equivalendo a 1.200 por parcela, com uma área útil de colheita de $3 \mathrm{~m}^{2}$. As linhagens e os cultivares atualmente comerciais estudados, em número de 25 , foram descritos em 2.1.

Em 1982, foram semeados três ensaios nos seguintes locais: Centro Experimental de Campinas e Estações Experimentais de Capão Bonito e de Tietê. Em 1983, foram instalados três experimentos nos locais de 1982, à exceção do de Tietê, que foi plantado na Fazenda Floresta Negra, município de Maracai.

$\mathrm{Na}$ instalação dos ensaios, retiraram-se amostras compostas dos solos dos locais estudados, tendo sido os resultados analíticos obtidos pela Seção de Fertilidade do Solo do Instituto Agronômico.

Os experimentos conduzidos em Campinas, nos anos considerados, foram irrigados por aspersão, e os das demais localidades não foram irrigados.

Foram coletados os seguintes dados:

Ferrugem-do-colmo e da folha: Avaliada através de observação geral, em cada parcela, no colmo e nas folhas superiores das plantas, no estádio de início de maturação, em condiçðes naturais de infecção, usando-se a escala modificada de Cobb, para avaliação da resistência no Ensaio Internacional de Ferrugem do Trigo (International Spring Wheat Rust Nursery), empregada por SCHRAM et alii (1974). Essa escala vai de 0 a $99 \%$ de área foliar infectada, complementada pelo tipo de reação: $S=$ suscetível (uredossoro grande, coalescente, sem necrose e sem clorose); $\mathrm{MS}=$ moderadamente suscetível (uredossoro médio); $\mathbf{M}=$ intermediário (diversos tipos de reação); $\mathrm{MR}=$ moderadamente resistente (uredossoro pequeno); $\mathrm{R}=$ resistente (uredossoro minúsculo, rodeado de áreas necróticas).

Outras moléstias da folha e da espiga: A avaliação de manchas foliares causadas por Helminthosporium sp. e Septoria sp. e de moléstias de espiga por Gibberella sp. e Helminthosporium sp. efetuou-se em planta adulta, em condições naturais de infecção, empregando-se uma escala de 0 a $99 \%$ 
de área infectada, apresentada por MEHTA (1978), onde 0 é considerado imune; 1 a $5 \%$ resistente; 6 a $25 \%$ moderadamente resistente; 26 a $50 \%$ suscetível e 51 a $99 \%$ altamente suscetível.

Ciclo da emergência ao florescimento: Efetuando contagens por parcela individual do número de dias da emergência das plântulas ao pleno florescimento.

Ciclo da emergência à maturação: Efetuando contagens por parcela individual do número de dias da emergência das plântulas à maturação fisiológica.

Plantas acamadas: Considerando a percentagem de plantas acamadas em cada parcela, por avaliação visual próxima à época de maturação.

Altura das plantas: Medida no campo, na época de maturação, a distância, em centímetros, do nível do solo ao ápice da espiga, excluindo as aristas, e levando em consideração a média de diferentes pontos de cada parcela.

Comprimento da espiga: Considerando o comprimento médio, em centímetros, de vinte espigas tomadas ao acaso de cada parcela, com exclusão das aristas.

Número de espiguetas: Computando o número médio de espiguetas de vinte espigas tomadas ao acaso de cada parcela.

Grãos por espiga: Considerando o número médio de grãos contados em vinte espigas colhidas ao acaso de cada parcela.

Grãos por espigueta: Calculando pela divisão do número total de grãos de vinte espigas, coletadas ao acaso de cada parcela, pelo número tota] de suas espiguetas.

Peso de cem grãos: Considerando o peso, em gramas, de cem grãos tomados ao acaso da produção total de cada parcela.

Produção de grãos: Pesando, em gramas, a produção total de grãos de cada parcela, a qual foi transformada para quilograma/hectare.

\subsection{Ensaios em condição de casa de vegetação e laboratório}

Resistência a raças dos agentes causais de ferrugem-do-colmo e da-folha

As sementes das linhagens e cultivares estudados foram remetidas ao Centro Nacional de Pesquisa de Trigo da EMBRAPA, Passo Fundo (RS), para identificação, quanto à resistência em estádio de plântula, em condições de casa de vegetação, a algumas raças de $P$. graminis tritici (G-7, G-9, G-15, G-17, G-18, G-19 e G-20) e de $P$. recondita (B, B-10, B-12, B-20 e B-26), de ocorrência comum no Brasil (BARCELLOS, 1985, e COELHO, 1985). 
Tolerância à toxicidade de alumínio

As linhagens e cultivares foram testados para tolerância a $0,3,6$ e $10 \mathrm{mg} /$ litro de $\mathrm{Al}^{3+}$ em soluções nutritivas, conforme método já publicado (CAMARGO \& OLIVEIRA, 1981, CAMARGO et alii, 1980, e MOORE et alii, 1976) e descrito a seguir:

As sementes das 21 linhagens e quatro cultivares foram cuidadosamente lavadas com uma solução de hipoclorito de sódio a $10 \%$ e colocadas para germinar em caixas de Petri por 24 horas. Após este tempo, as radículas estavam iniciando a emergência.

Em cada uma das duas repetições, foram utilizadas quatro telas de náilon, contendo cada uma vinte sementes uniformes de cada uma das linhagens e cultivares em estudo. As telas contendo as sementes foram colocadas em contacto com a solução nutritiva completa existente em quatro vasilhas plásticas de 8,3 litros de capacidade cada uma. A composição da solução nutritiva completa foi a seguinte: $\mathrm{Ca}\left(\mathrm{NO}_{3}\right)_{2} 4 \mathrm{mM} ; \mathrm{MgSO}_{4} 2 \mathrm{mM} ; \mathrm{KNO}_{3}$ $4 \mathrm{mM} ;\left(\mathrm{NH}_{4}\right)_{2} \mathrm{SO}_{4} 0,435 \mathrm{mM} ; \mathrm{KH}_{2} \mathrm{PO}_{4} 0,5 \mathrm{mM} ; \mathrm{MnSO}_{4} 2 \mu \mathrm{M} ; \mathrm{CuSO}_{4}$ $0,3 \mu \mathrm{M} ; \mathrm{ZnSO}_{4} \quad 0,8 \mu \mathrm{M} ; \mathrm{NaCl} 30 \mu \mathrm{M} ; \mathrm{Fe}-\mathrm{CYDTA} 10 \mu \mathrm{M} ; \mathrm{Na}_{2} \mathrm{MoO}_{4} 0,1 \mu \mathrm{M}$ e $\mathrm{H}_{3} \mathrm{BO}_{3} 10 \mu \mathrm{M}$.

O nível da solução nas vasilhas plásticas tocava a parte de baixo da tela de náilon, de modo que as sementes foram mantidas úmidas e as radículas emergentes tinham um pronto suprimento de nutrientes. $\mathrm{O} \mathrm{pH}$ das solução foi previamente ajustado para $4,0 \mathrm{com}$ uma solução de $\mathrm{H}_{2} \mathrm{SO}_{4} 1 \mathrm{~N}$ e, as vasilhas plásticas contendo as soluções, colocadas em banho-maria com temperatura de $25 \pm 1^{\circ} \mathrm{C}$ dentro do laboratório.

As plântulas desenvolveram-se nessas condições por 48 horas. Findo esse periodo, cada plântula tinha três raízes primárias, uma mais longa e duas mais curtas, localizadas lateralmente à primeira.

As quatro telas contendo as vinte plântulas de cada linhagem ou cultivar foram a seguir colocadas em contacto com quatro soluções de tratamento com um décimo da concentração de sais da solução completa contendo cada uma $0,3,6$ e $10 \mathrm{mg} /$ litro de $\mathrm{Al}^{3+}$.

Nas soluções de tratamento, o fósforo foi omitido e o ferro, adicionado em quantidade equivalente àquela colocada na solução completa como $\mathrm{FeCl}_{3}$ no lugar do Fe-CYDTA, como descrito por MOORE et alii (1976). O fósforo foi omitido, para evitar a possível precipitação do alumínio. Antes da transferência das telas contendo as plântulas para as soluçðes de tratamento, foi adicionada a quantidade necessária de $\mathrm{Al}_{2}\left(\mathrm{SO}_{4}\right)_{3}$, de modo a serem obtidas as concentrações desejadas de alumínio. Em seguida, foi acrescentada suficiente solução de $\mathrm{H}_{2} \mathrm{SO}_{4} 1 \mathrm{~N}$ para obter $\mathrm{pH} 4,0$.

As plântulas permaneceram crescendo por 48 horas nas soluções de 
tratamento em banho-maria com temperatura de $25 \pm 1^{\circ} \mathrm{C}$. Decorrido esse período, as telas contendo as plantas foram transferidas de volta para as quatro vasilhas plásticas com soluções nutritivas completas (sem alumínio), permanecendo por mais 72 horas, à mesma temperatura.

A quantidade de crescimento da raiz de cada plântula foi determinada, medindo-se o comprimento da raiz primária central, no final das 72 horas de crescimento na solução nutritiva completa, subtraindo-se do comprimento da mesma raiz, no final do crescimento na solução de tratamento.

Durante todo o experimento, empregaram-se luz fluorescente e arejamento das soluçôes, e o $\mathrm{pH}$ das soluções nutritivas completas e de tratamento foi mantido o mais próximo possível de 4,0 , por ajustamentos diários com uma solução de $\mathrm{H}_{2} \mathrm{SO}_{4} 1 \mathrm{~N}$.

\section{RESULTADOS E DISCUSSÃO}

As produções médias de grãos transformadas em quilograma/hectare das linhagens e cultivares de trigo estudados em 1982 e 1983, em diferentes regiōes do Estado de São Paulo, encontram-se no quadro 1. Os resultados da análise estatística dos seis experimentos, analisados separadamente, mostraram efeitos altamente significativos para linhagens e cultivares.

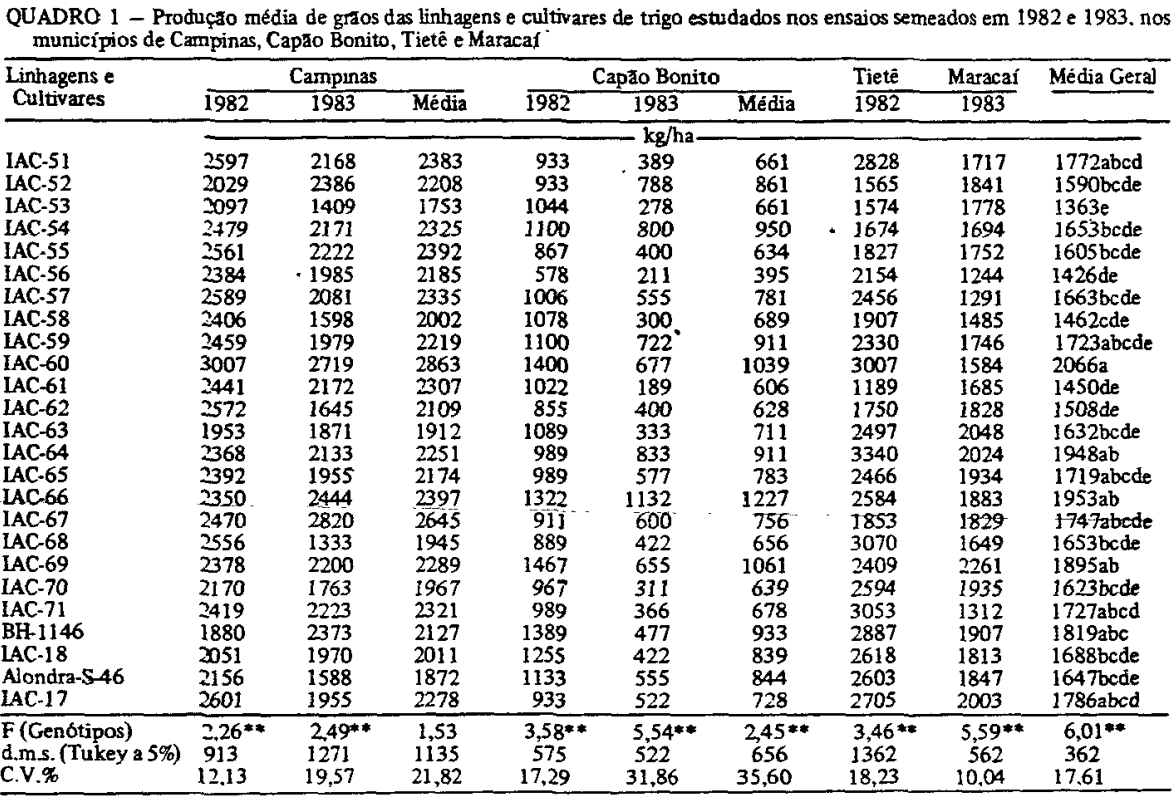

**=-Signi ficativo ao nivel de $1 \%$ * = Significativo ao nrvel de $5 \%$. 
Considerando em conjunto os ensaios plantados em Campinas, em 1982 e 1983, verificaram-se pela análise de variância efeitos altamente significativos para anos e não-significativos para tratamentos.

Através do teste de Tukey aplicado ao nível de 5\% para a comparação das médias nos tratamentos no ensaio de linhagens e cultivares instalados em Campinas, em 1982, em condição de irrigação por aspersão, verificou-se que apenas IAC-60, que produziu $3.007 \mathrm{~kg} / \mathrm{ha}$, diferiu significativamente do 'BH-1 146', com $1.880 \mathrm{~kg} / \mathrm{ha}$. No ensaio instalado em 1983 , em Campinas, destacaram-se, quanto à produção de grãos, as linhagens IAC-60 e IAC-67, que somente diferiram estatisticamente das linhagens menos produtivas: IAC-53 e IAC-68. Considerando em conjunto os experimentos conduzidos em Campinas, observou-se que as linhagens IAC-60 e IAC-67 produziram respectivamente 2863 e $2645 \mathrm{~kg} / \mathrm{ha}$, enquanto 'BH-1146' produziu $2127 \mathrm{~kg} / \mathrm{ha}$; contudo, não foram observadas diferenças significativas entre os tratamentos devidas a uma alta interação tratamento $\mathrm{x}$ ano.

No ensaio plantado em Capão Bonito, em 1982, a linhagem IAC-69 obteve a maior produção de grãos, diferindo ao nível de $5 \%$ apenas das linhagens IAC-55, IAC-56 e IAC-62. Em 1983, a linhagem IAC-66 mostrou a maior produção, diferindo das demais, com exceção das linhagens IAC-52, IAC-54, IAC-59, IAC-60, IAC-64 e IAC-69. Considerando em conjunto os dois ensaios, verificou-se que as linhagens IAC-66, IAC-60 e IAC-69 foram as mais produtivas, somente diferindo, porém ao nível de $5 \%$, da linhagem IAC-56.

A linhagem IAC-64 destacou-se quanto à produção de grãos no ensaio instalado em Tietê, em 1982, diferindo somente, porém, ao nível de 5\%, das linhagens IAC-52, IAC-53, IAC-54, IAC-55, IAC-58, IAC-61, IAC-62 e IAC-67.

No ensaio plantado em Maracaí, em 1983, destacou-se quanto à produção de grãos a linhagem IAC-69, que diferiu ao nivel de $5 \%$ das linhagens IAC-54, IAC-56, IAC-57, IAC-58, IAC-60 e IAC-61. As linhagens IAC63 e IAC-64 também mostraram adaptação ao solo de alta fertilidade de Maracaí, exibindo boa produtividade.

Analisando em conjunto os seis ensaios, verificaram-se efeitos altamente significativos para genótipo, ensaio e interação genótipo $\mathrm{x}$ ensaio. Pelo teste de Tukey, observou-se que IAC-60, IAC-66, IAC-64 e IAC-69 foram os mais produtivos, porém não diferiram dos cultivares controles $\mathrm{BH}-1146 \mathrm{e}$ IAC-17. Somente a linhagem IAC-60 diferiu dos cultivares controles Alondra-S-46 e IAC-1 8.

Nos seis ensaios considerados, os graus máximos de infecção de ferrugem-do-colmo e da-folha, bem como de outras moléstias da parte aérea, nas linhagens e cultivares estudados, encontram-se no quadro 2. 
QUADRO 2 - Graus máximos de infeç̧ão (porcentagem de área infectada e tipo de pústula) de ferrugens-do-colmo e da-folha, doenças da folha e espiga, em estádio de planta adulta, nos ensaios de linhagens e cultivares semeados em 1982 e 1983, nos municípios de Campinas, Capão Bonito, Tietê e Maracaí

\begin{tabular}{lcccc}
\hline $\begin{array}{l}\text { Cultivares e } \\
\text { linhagens }\end{array}$ & $\begin{array}{c}\text { Ferrugem- } \\
\text {-do-colmo }\end{array}$ & $\begin{array}{c}\text { Ferrugem- } \\
\text {-da-folha }\end{array}$ & $\begin{array}{c}\text { Helmintos- } \\
\text { poriose }\end{array}$ & $\begin{array}{c}\text { Doença de } \\
\text { espiga }\end{array}$ \\
\hline IAC-51 & $5 S$ & $10 S$ & 40 & 50 \\
IAC-52 & $5 S$ & $30 S$ & 40 & 50 \\
IAC-53 & $5 S$ & $30 S$ & 50 & 60 \\
IAC-54 & 0 & $30 S$ & 50 & 30 \\
IAC-55 & tS & $20 S$ & 50 & 50 \\
IAC-56 & 0 & $5 S$ & 60 & 60 \\
IAC-57 & $5 S$ & $30 S$ & 50 & 50 \\
IAC-58 & $5 S$ & $30 S$ & 50 & 60 \\
IAC-59 & tS & $30 S$ & 50 & 50 \\
IAC-60 & $5 S$ & $30 S$ & 50 & 40 \\
IAC-61 & 0 & $10 S$ & 40 & 40 \\
IAC-62 & tS & $10 S$ & 50 & 50 \\
IAC-63 & $20 S$ & $10 S$ & 50 & 60 \\
IAC-64 & 0 & $30 S$ & 40 & 40 \\
IAC-65 & tS & $20 S$ & 50 & 40 \\
IAC-66 & 0 & $20 S$ & 40 & 30 \\
IAC-67 & 0 & $10 S$ & 50 & 40 \\
IAC-68 & $40 S$ & $40 S$ & 40 & 40 \\
IAC-69 & tS & $40 S$ & 40 & 40 \\
IAC-70 & $30 S$ & $30 S$ & 40 & 50 \\
IAC-71 & $10 S$ & $20 S$ & 60 & 50 \\
BH-1146 & $50 S$ & $30 S$ & 30 & 30 \\
IAC-18 & $20 S$ & $30 S$ & 40 & 40 \\
Alondra-S-46 & 0 & $30 S$ & 50 & 50 \\
IAC-17 & $20 S$ & $30 S$ & 40 & 20 \\
\hline
\end{tabular}

$t=$ traços (apenas algumas pústulas).

$\mathrm{S}=$ reação de suscetibilidade.

As linhagens IAC-51, IAC-52, IAC-53, IAC-54, IAC-55, IAC-56, IAC-57, IAC-58, IAC-59, IAC-60, IAC-61, IAC-62, IAC-64, IAC-65, IAC-66, IAC-67 e IAC-69 e o cultivar Alondra-S-46 mostraram-se resistentes à ferru- 
gem-do-colmo em condições naturais de infecção, exibindo reações iguais ou inferiores a $5 \mathrm{~S}$. Nessa mesma situação, o cultivar BH-1146, suscetivel à ferrugem-do-colmo, exibiu um grau de infecção máximo de 50S. As linhagens IAC-53, IAC-56, IAC-61 e IAC-62 apresentaram produções significativamente inferiores ao cultivar $\mathrm{BH}-1146$, porém apresentaram menor suscetibilidade à ferrugem-do-colmo em condições de campo, podendo ser aproveitadas em cruzamentos no programa de melhoramento.

Em relação à ferrugem-da-folha, destacaram-se, quanto à resistência em planta adulta, as linhagens IAC-51, IAC-56, IAC-61, IAC-62, IAC-63 e IAC-67 com graus de infecção inferiores aos encontrados nos cultivares considerados controles BH-1146, IAC-17, IAC-18 e Alondra-S-46.

A ocorrência de helmintosporiose foi bastante acentuada no ensaio plantado em Capão Bonito em 1983, sendo suscetíveis praticamente todas as linhagens, bem como os cultivares. Destes, 'BH-1146' foi o que apresentou menor intensidade de ataque. Com relação à helmintosporiose e giberela, observou-se, nas espigas, menor intensidade de ataque nas linhagens IAC-54 e IAC-66 e nos cultivares BH-1146 e IAC-17.

As reações das linhagens e cultivares (estádio de plântula) a Puccinia graminis f. sp. tritici e $P$. recondita, em condições de casa de vegetação, encontram-se no quadro 3. As linhagens IAC-62 e IAC-65 apresentaram-se resistentes às sete raças do agente causal da ferrugem-do-colmo em condiçōes de casa de vegetação e de campo. O mesmo comportamento foi observado para 'Alondra-S-46'. A linhagem IAC-64 mostrou-se resistente a quatro raças de $P$. recondita e as linhagens IAC-52 e IAC-55 apresentaram resistência a três raças, em casa de vegetação. Essas linhagens em condição de campo revelaram reações máximas de 20 a $30 \mathrm{~S}$ de ferrugem-da-follha, mostrando, portanto, um grau de suscetibilidade que poderia ser devido à ocorrencia de uma ou mais raças não prevalentes em condição de infecção natural: tais raças não foram detectadas no levantamento, e para elas as linhagens não foram testadas em estádio de plântula, em casa de vegetação. Segundo COELHO (1983), as raças G-15, G17, G-19 e G-20 foram as prevalentes nos últimos anos no Estado de São Paulo.

Os cultivares comerciais $\mathrm{BH}-1146$ e IAC-18 foram suscetiveis, respectivamente, a sete e a seis raças de ferrugem-do-colmo, e ambos foram também suscetíveis a quatro raças de ferrugem-da-folha no estádio de plântula. Apesar da sua suscetibilidade a várias raças dos patógenos das ferrugens, verificou-se, em condição de campo, em 1982 e 1983, que o grau máximo de infecção não ultrapassou $50 \mathrm{~S}$ para ferrugem-do-colmo e $30 \mathrm{~S}$ para ferrugemda-folha, o que decorreu provavelmente de condições desfavoráveis ao desenvolvimento dos fungos ou de sua incidência tardia.

O ciclo em dias da emergência ao florescimento e da emergência à 
QUADRO 3 - Reaçōes das linhagens e cultivares (estádio de plântulas) às raças de Puccinia graminis f. sp. tritici e P. reconditu, em condiços controladas de casa de vegetaçăo

\begin{tabular}{|c|c|c|c|c|c|c|c|c|c|c|c|c|}
\hline \multirow{2}{*}{$\begin{array}{l}\text { Cul tivares e } \\
\text { linhagens }\end{array}$} & \multicolumn{7}{|c|}{ Raças de Puccinia graminis f. sp. tritici } & \multicolumn{5}{|c|}{ Raças de Puccinia recondita } \\
\hline & $\overline{\mathrm{G} 7}$ & G9 & G 15 & $\mathrm{G} 17$ & G 18 & G 19 & G 20 & $\overline{B 10}$ & B 12 & B 20 & B 26 & $\bar{B}$ \\
\hline IAC-51 & - & 1 & 4 & $2+$ & $3-$ & - & 3 & - & $2+$ & - & 3 & $3 \mathrm{PO}$ \\
\hline IAC-52 & $3-$ & 1 & 3 & $2+$ & 3 & 3 & 4 & 2 & 2 & 2 & 3 & - \\
\hline IAC. 53 & $2+$ & 0 & 4 & $2+$ & 4 & 4 & 3 & - & $2-$ & 2 & 3 & $\mathrm{PO}$ e 3 \\
\hline IAC-54 & - & - & 3 & $2+$ & - & $3-$ & $2++$ & $2-$ & 2 & - & 3 & $\mathrm{PO}$ e 3 \\
\hline IAC- 55 & - & 0 & 2 e 3 & $2+$ & $2++$ & $3-$ & $3-$ & $2-$ & 2 & 2 & $4 \mathrm{P} 3$ & $\mathrm{PO}$ e 3 \\
\hline IAC-56 & 2 & - & $2 \mathrm{e} 3$ & $0 ;$ e 2 & 2 & $2++$ & 2 e 3 & - & 1 & - & - & $\mathrm{PO}$ e 3 \\
\hline IAC. 57 & - & 0 & 0 ; e 2 & $0 ;$ e 2 & - & $2 \mathrm{e} 3$ & $2+$ & 3 & 3 & - & 3 & 0 \\
\hline LAC- 58 & $2++$ & 2 & $0 ;$ e 3 & $2++$ & $0 ;$ e 4 & 3 & $2++$ & - & 2 & 2 & 3 & 3 \\
\hline IAC-59 & - & 2 & 0 & 0 & 0 & $2++$ & $0 ; \mathrm{e}^{2++}$ & 3 & 3 & 3 & - & 3 \\
\hline IAC -60 & - & 0 & 0 & 0 & 0 & $3-$ & 4 & 3 & 3 & 3 & 3 & 3 \\
\hline LAC-61 & 2 & 2 & $0 ;$ e 4 & $0 ;$ e 1 & 0 & 2 & 4 & 3 & 3 & $2 \mathrm{P} 3$ & - & 3 \\
\hline IAC- 62 & 0 & 2 & 0 & 0 & 0 & 1 & 0 & - & - & - & - & 3 \\
\hline IAC -63 & - & - & - & 0 & 0 & - & - & P03 & - & 0 & - & 0 \\
\hline IAC- 64 & - & - & 0 ; & 0 & 0 & 1 & 0 & 0 & 0 & 0 & - & 0 \\
\hline IAC. 65 & 0 & 0 & 0 & 0 & 0 & $1-$ & $0 ; 2 \mathrm{P} 4$ & - & - & 0 & - & 0 \\
\hline IAC-66 & - & $0 ;$ & $2+$ & $2-$ & - & $1-$ & $2++$ & 3 & $2 \mathrm{P} 3$ & 2PO & 3 & 0 \\
\hline LAC -67 & 0 & - & 1 & 0 & 0 & 2 & $2 \mathrm{e} 3$ & 3 & $3 \mathrm{P} 3$ & - & 3 & 3 \\
\hline IAC-68 & - & 2 & 4 & 3 & 4 & 3 & $1 \mathrm{P} 4$ & $3 \mathrm{P} 3$ & 3 & - & 3 & 3 \\
\hline IAC- 69 & 0 & 3 & 0 ; & 0 & 0 & 1 & 4 & 0 & $\mathrm{PO}$ e 3 & 0 ; & 3 & 3 \\
\hline IAC-70 & - & - & - & - & - & - & - & $1 \mathrm{P3}$ & - & - & 3 & - \\
\hline IAC-71 & 1 & 1 & 0 & 0 & 0 & 3 & 4 & 0 & 3 & 0 & 3 & 3 \\
\hline BH-1146 & 4 & 4 & 4 & 4 & 4 & 3 & 4 & 3 & 3 & 3 & 3 & - \\
\hline IAC-18 & 0 & 4 & 3 & 4 & 4 & 3 & 4 & 3- & 3- & 3 & 3 & - \\
\hline Alondra-S-46 & 0 & 0 & 0 & 0 & 0 & 0 & 0 & 0 & $0 ; 1$ P3 & 0 & - & - \\
\hline LAC-17 & 0 & 0 & 3 & 2 e 4 & $0 ;$ e 4 & 3 & 4 & $3-$ & $3-$ & 3 & - & - \\
\hline
\end{tabular}

$0=$ imune; $0 ; 1,1$ - e 2 resistente $; 2+$ e $2++=$ moderadamente resistente; 3 - e $3--=$ moderadamente suscetivel 3 e $4=$ sus cetível, $\mathrm{P}=$ planta; $3 \mathrm{PO}=3$ plantas com reaçăo imune; $\mathrm{P0}$ e $3=$ plantas com reação imune e com reaçāo suscetivel.

maturação, a porcentagem de plantas acamadas, a altura da planta, o comprimento da espiga, o número de grãos por espiga e por espigueta, o número de espiguetas e o peso de cem grãos das linhagens e cultivares estudados nos seis ensaios, encontram-se no quadro 4. As linhagens IAC-63, IAC-68, IAC-69 e IAC-71, foram tão precoces quanto os cultivares comerciais IAC-17, IAC-1 8 e $\mathrm{BH}-1146$, sendo que as demais linhagens demonstraram um ciclo médio semelhante ao 'Alondra-S-46'.

As linhagens IAC-52, IAC-53, IAC-54, IAC-55, IAC-56, IAC-57, IAC-58, IAC-60, IAC-64, IAC-65, IAC-67, IAC-71 e o cultivar Alondra-S-46 mostraram plantas significativamente mais baixas que as do cultivar $\mathrm{BH}$ 1146. Considerando que esses germoplasmas também não exibiram plantas acamadas, estariam, portanto, entre aqueles com potencial de cultivo em condição de irrigação. As linhagens IAC-51, IAC-59, IAC-61, IAC-62, IAC-63, IAC-68, IAC-69 e IAC-70 e os cultivares BH-1146, IAC-1 7 e IAC-1 8 apresentaram-se sensíveis ao acamamento, que foi associado a um porte de planta de médio para alto. Tais germoplasmas não seriam indicados para condições irrigadas, pois suas produções poderiam ser prejudicadas pelo acamamento, quando em condições de colh eita mecânica.

A linhagem IAC-59 foi a que mostrou espigas mais compridas, diferindo estatisticamente das demais linhagens e cultivares estudados, com exceção do IAC-54, IAC-55, IAC-57, IAC-60, IAC-61, IAC-64, IAC-65, IAC- 
QUADRO 4 - Dados médios referentes a ciclo da emergência ao florescimento e da emergência à maturaçăo, porcentagem de plantas acamadas, altura da planta, comprimento da espiga, número de gråos por espiga e por espigueta, número de espiguetas, peso de cem gräos das linhagens e cultivares de trigo semeados em 1982 e 1983, nos municipios de Campinas, Capão Bonito,

\begin{tabular}{|c|c|c|c|c|c|c|c|c|c|}
\hline \multirow{2}{*}{$\begin{array}{l}\text { Linhagens e } \\
\text { cultivares }\end{array}$} & \multicolumn{2}{|c|}{ Ciclo } & \multirow{2}{*}{$\begin{array}{c}\text { Plantas } \\
\text { acamadas } \\
\end{array}$} & \multirow{2}{*}{$\begin{array}{l}\text { Altura da } \\
\text { planta }\end{array}$} & \multirow{2}{*}{$\begin{array}{l}\text { Compr. } \\
\text { espiga }\end{array}$} & \multirow{2}{*}{$\begin{array}{l}\text { Grãos/ } \\
\text { /espiga }\end{array}$} & \multirow{2}{*}{$\begin{array}{l}\text { Grãos/ } \\
\text { /espigueta }\end{array}$} & \multirow{2}{*}{ Espiguetas } & \multirow{2}{*}{$\begin{array}{l}\text { Peso de } \\
\text { cem grāos }\end{array}$} \\
\hline & $\begin{array}{l}\text { Emerg. } \\
\text { flor. }\end{array}$ & $\begin{array}{c}\text { Emerg. } \\
\text { mat. }\end{array}$ & & & & & & & \\
\hline & \multicolumn{2}{|c|}{ dias } & $q$ & $\mathrm{~cm}$ & $\mathrm{~cm}$ & nọ & 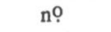 & $\mathrm{n}$ ? & g \\
\hline IAC-51 & 68 & 111 & $0-20$ & 104 & 7,8 & 36,8 & 2,00 & 19,0 & 4,61 \\
\hline IAC -52 & 72 & 125 & 0 & 79 & 8,0 & 52,9 & 2,40 & 22,1 & 3,26 \\
\hline IAC -53 & 73 & 122 & 0 & 74 & 8,0 & 53,8 & 2,50 & 21,6 & 3,47 \\
\hline IAC-54 & 73 & 123 & 0 & 77 & 9,3 & 49,0 & 2,21 & 22,2 & 3,34 \\
\hline IAC. 55 & 71 & 114 & 0 & 76 & 9,0 & 46,8 & 2,14 & 21,9 & 3,64 \\
\hline IAC-56 & 68 & 112 & 0 & 73 & 7,8 & 45,3 & 2,48 & 18,3 & 3,06 \\
\hline LAC-57 & 70 & 111 & 0 & 71 & 8,9 & 48,9 & 2,24 & 21,8 & 3,30 \\
\hline LAC-58 & 73 & 117 & 0 & 69 & 7,7 & 48,0 & 2,35 & 20,4 & 2,71 \\
\hline IAC. 59 & 70 & 116 & 0.20 & 111 & 10,5 & 44,7 & 1,98 & 22,6 & 4,24 \\
\hline IAC-60 & 68 & 114 & 0 & 83 & 9,3 & 53,1 & 2,37 & 22,4 & 3,56 \\
\hline IAC-61 & 70 & 117 & $40-60$ & 103 & 9,4 & 43,8 & 2,13 & 20,6 & 3,76 \\
\hline IAC-62 & 71 & 114 & $20-40$ & 104 & $8,8^{1}$ & 32,6 & 1,83 & 17,8 & 4,87 \\
\hline IAC- 63 & 64 & 106 & 0.20 & 101 & 8,4 & 36,1 & 2,26 & 15,9 & 4,31 \\
\hline IAC-64 & 72 & 116 & 0 & 85 & 10,0 & 39,8 & 1,95 & 20,5 & 4,25 \\
\hline LAC- 65 & 71 & 114 & 0 & 78 & 10,4 & 43,6 & 2,16 & 20,1 & 4,11 \\
\hline IAC-66 & 76 & 123 & 0 & 89 & 9,0 & 42,0 & 1,99 & 21,9 & 3,71 \\
\hline IAC- 67 & 70 & 122 & 0 & 77 & 7,9 & 39,4 & 2,16 & 18,2 & 4,46 \\
\hline [AC-68 & 64 & 107 & $0-20$ & 102 & 7,6 & 38,3 & 2,08 & 18,4 & 2,71 \\
\hline IAC- 69 & 64 & 106 & $20-40$ & 97 & 6,9 & 38,9 & 2,35 & 16,5 & 2,22 \\
\hline IAC-70 & 70 & 114 & $20-40$ & 102 & 9,2 & 42,7 & 2,10 & 20,3 & 4,26 \\
\hline IAC-71 & 62 & 107 & 0 & 77 & 7,3 & 28,6 & 1,61 & 17,8 & 4,32 \\
\hline $\mathrm{BH}-1146$ & 63 & 105 & $40-60$ & 101 & 7,4 & 33,4 & 1,86 & 17,3 & 2,74 \\
\hline LAC-18 & 64 & 105 & $40-60$ & 99 & 7,4 & 31,7 & 1,78 & 17,9 & 2,71 \\
\hline Alondra-S-46 & 73 & 122 & 0 & 80 & 9,5 & . 39,5 & 2,09 & 18,8 & 3,91 \\
\hline IAC-17 & 62 & 105 & $40-60$ & 91 & 7,6 & 31,0 & 1,75 & 17,8 & 3.13 \\
\hline F (Genótipos) & & & & $22,64 *$ & $12,48^{* *}$ & $12,99 * *$ & $5,61^{* *}$ & $16,69^{* *}$ & $26,10^{* *}$ \\
\hline d.m.s. (Tukey 5\%) & & & & 15 & 1,6 & 10,9 & 0,54 & 2,7 & 0,75 \\
\hline C.V.(\%) & & & & 5,41 & 5,75 & 8,27 & 8,10 & 4,37 & 6,55 \\
\hline
\end{tabular}

66, IAC-70 e Alondra-S-46. A linhagem IAC-53 apresentou o maior número de grãos por espiga, não diferindo das linhagens IAC-52, IAC-54, IAC-55, IAC-56, IAC-57, IAC-58, IAC-59, IAC-60, IAC-61 e IAC-65; diferiu, porém, dos demais germoplasmas considerados. A IAC-53 também exibiu espigas com maior fertilidade, isto é, com maior número de grãos por espigueta, diferindo estatisticamente das linhagens IAC-62, IAC-64 e IAC-71 e dos cultivares BH-1 146, IAC-17 e IAC-18.

O comprimento médio das raizes das 21 linhagens e 4 cultivares de trigo medidos após 72 horas de crescimento nas soluções nutritivas completas, seguido de 48 horas de crescimento nas soluções de tratamento contendo quatro diferentes concentrações de alumínio, encontram-se no quadro 5 . Considerando $3 \mathrm{mg} /$ litro de $\mathrm{Al}^{3+}$, pode-se verificar que a linhagem IAC-55 foi sensivel a essa concentração, e as demais, tolerantes.

As linhagens IAC-52, IAC-54, IAC-56, IAC-61, IAC-62, IAC-64, IAC-65 e IAC-67 e o cultivar Alondra-S-46 foram tolerantes a $3 \mathrm{mg} / \mathrm{litro}$ de $\mathrm{Al}^{3+}$ na solução tratamento, porém exibiram sensibilidade quando se empregaram soluções com $6 \mathrm{mg} /$ litro de $\mathrm{Al}^{3+}$, sendo, portanto, considerados como moderadamente sensiveis. 
QUADRO 5 - Comprimento médio das raízes das linhagens e cultivares de trigo, medidos após 72 horas de crescimento na solução nutritiva completa, seguido de crescimento na solução de tratamento contendo quatro concentraçбes de $\mathrm{Al}^{3+}$

\begin{tabular}{|c|c|c|c|c|}
\hline \multirow{2}{*}{$\begin{array}{c}\text { Cultivares e } \\
\text { linhagens }\end{array}$} & \multicolumn{4}{|c|}{ Concentração de aluminio (mg/litro) } \\
\hline & 0 & 3 & 6 & 10 \\
\hline IAC-51 & 66,9 & 14,4 & 16,7 & 8,4 \\
\hline IAC-52 & 49,7 & 24,7 & 0,0 & 0,0 \\
\hline IAC. 53 & 48,9 & 34,3 & 3,5 & 0,0 \\
\hline IAC-54 & 63,0 & 5,3 & 0,0 & 0,0 \\
\hline IAC-55 & 49,7 & 0,0 & 0,0 & 0,0 \\
\hline IAC-56 & 48,6 & 10,1 & 0,0 & 0,0 \\
\hline LAC-57 & 45,0 & 47,2 & 0,4 & 0,0 \\
\hline IAC-58 & 50,8 & 39,6 & 0,6 & 0,0 \\
\hline IAC-59 & 36,8 & 17,8 & 0,1 & 0,0 \\
\hline IAC-60 & 59,0 & 61,9 & 19,4 & 3,3 \\
\hline IAC-61 & 62,1 & 0,5 & 0,0 & 0,0 \\
\hline IAC- 62 & 54,0 & 25,8 & 0,0 & 0,0 \\
\hline IAC-63 & 60,1 & 54,0 & 19,9 & 3,4 \\
\hline IAC-64 & 21,1 & 14,0 & 0,0 & 0,0 \\
\hline IAC-65 & 39,5 & 11,7 & 0,0 & 0,0 \\
\hline IAC-66 & 53,7 & 42,7 & 2,6 & 0,0 \\
\hline IAC-67 & 60,6 & 43,3 & 0,0 & 0,0 \\
\hline IAC-68 & 57,9 & 62,0 & 40,5 & 5,8 \\
\hline IAC-69 & 45,7 & 52,1 & 5,9 & 0,0 \\
\hline IAC-70 & 49,0 & 35,6 & 7,9 & 3,1 \\
\hline IAC-71 & 73,1 & 46,1 & 1,8 & 0,0 \\
\hline BH-1146 & 68,9 & 70,7 & 40,3 & 23,9 \\
\hline IAC-18 & 58,3 & 64,7 & 35,1 & 8,3 \\
\hline Alondra-S-46 & 48,0 & 15,0 & 0,0 & 0,0 \\
\hline IAC-17 & 65,0 & 49,1 & 14,3 & 0,0 \\
\hline
\end{tabular}

As linhagens IAC-53, IAC-57, IAC-58, IAC-59, IAC-66, IAC-69 e IAC-71 e o cultivar IAC-17, foram tolerantes a $6 \mathrm{mg} /$ litro de $\mathrm{Al}^{3+}$, porém demostraram sensibilidade à presença de $10 \mathrm{mg} /$ litro de $\mathrm{Al}^{3+}$ nas soluções de tratamento. Esses germoplasmas foram considerados moderadamente tolerantes. 
Os cultivares $\mathrm{BH}-1146$ e IAC-18, bem como as linhagens IAC-51, IAC-60, IAC-63, IAC-68 e IAC-70 apresentaram-se como tolerantes mesmo quando se adicionaram $10 \mathrm{mg} /$ litro de $\mathrm{Al}^{3+}$ nas soluções de tratamento.

\section{CONCLUSÕES}

a) Considerando-se os diversos parâmetros analisados, salientaram-se as linhagens IAC-60, IAC-64, IAC-66 e IAC-69 com boa produtividade e resistência à ferrugem-do-colmo, porte baixo a médio (exceto IAC-69), sendo tolerantes a moderadamente tolerantes à toxicidade de $\mathrm{Al}^{3+}$ (excluindo IAC-64). Essas linhagens deveriam ser trabalhadas visando a maior resistência à ferrugem-da-folha. Nas linhagens IAC-64 e IAC-69, haveria necessidade de incorporação de tolerância ao $\mathrm{Al}^{3+}$ e porte baixo respectivamente.

b) As linhagens IAC-62 e IAC-65 foram resistentes às sete raças testadas de ferrugem-do-colmo em casa de vegetação e em condições de campo. O mesmo comportamento foi encontrado para o cultivar Alondra-S-46.

c) Em casa de vegetação, a linhagem IAC-64 foi resistente a quatro raças de ferrugem-da-folha e IAC- 52 e IAC- 55 foram resistentes a três raças. Em condição de infecção natural em estádio de planta adulta, as linhagens IAC-51, IAC-56, IAC-61, IAC-62, IAC-63 e IAC-67 apresentaram-se com menor grau de infecção dessa ferrugem.

d) As linhagens IAC-52, IAC-53, IAC-54, IAC-55, IAC-56, IAC-57, IAC-58, IAC-60, IAC-64, IAC-65, IAC-67 e IAC-71 e o cultivar Alondra-S-46 mostraram plantas significativamente mais baixas que o ' $\mathrm{BH}-1146$ '.

e) A linhagem IAC-55 foi sensivel à toxicidade de $\mathrm{Al}^{3+}$. IAC-52, IAC-54, IAC-56, IAC-61, IAC-62, IAC-64, IAC-65 e IAC-67, e o 'Alondra-S46' foram moderadamente sensíveis; IAC-53, IAC-57, IAC-58, IAC-59, IAC-66, IAC-69, IAC-71 e IAC-17 foram moderadamente tolerantes e os cultivares BH-1146 e IAC-18 e as linhagens IAC-51, IAC-60, IAC-63, IAC-68 e IAC-70 apresentaram-se como tolerantes.

\section{SUMMARY \\ WHEAT BREEDING. \\ XII. EVALUATION OF NEW INBRED LINES FOR THE STATE OF SÃO PAULO, BRAZIL}

Twenty one inbred lines obtained at the Instituto Agronômico from the wheat breeding program plus the cultivars BH-1 146, IAC-18, IAC-17, and AlondraS-46 were evaluated in field experiments carried out at Campinas Experiment Center and Capão Bonito Experiment Station, during the years of 1982 and 1983, at Tietê Experiment Station, in 1982 and at Floresta Negra Farm, Maracaí, in 1983. Grain 
yield, plant height, number of days from emergence to flowering and from emergence to maturation, percentage of layed plants, head length, number of grain per spike and per spikelet, number of spikelets, weight of $100 \mathrm{grains}$, and resistance to stem and leaf rusts were evaluated under field conditions and tests of resistance to stem and leaf rusts and to aluminum were also made, respectively, in greenhouse and in laboratory. Considering the trials planted under sprinkler irrigation, at Campinas, the lines IAC-60 and IAC-67 showed good performance regarding to grain yield. In Capão Bonito, represented by acid soils, the lines IAC-66, IAC-60 and IAC-69 showed high grain yield. The lines IAC-64, IAC-68, IAC-71 and IAC-60 presented good productivity at Tietê Experiment Station and IAC-67, IAC-63 and IAC-64 were more adapted to high soil fertility showing the best grain yields at Maracaí. The lines IAC-52, IAC-53, IAC-54, IAC-55, IAC-56, IAC-57, IAC-58, IAC-60, IAC-64, IAC-65, IAC-67, IAC-71 and the cultivar Alondra-S-46 exhibited semidwarf type when compared to the tall cultivar BH-1146. In relation to stem rust, the lines IAC-62 and IAC- 65 and the cultivar Alondra-S-46 showed very good resistance presenting at seedling stage, resistance to seven races under both greenhouse and field conditions. The line IAC-64 was resistant to four and IAC-52 and IAC-55 to three races of leaf rust in the seedling stage under greenhouse condition. The lines IAC-51, IAC-56, IAC-61, IAC-62, IAC-63 and IAC-67 presented good resistance to this rust in natural infection out in the field. The lines IAC-51, IAC-60, IAC-63, IAC-68 and IAC-70 as well as 'BH-1146' and 'IAC-18' were tolerant to the presence of $10 \mathrm{mg} / 1$ of $\mathrm{Al}^{3+}$ in the nutrient solution.

Index terms: wheat, yield, plant height, stem and leaf rusts, tolerance, aluminum toxicity.

\section{REFERENCIAS BIBLIOGRÁFICAS}

ALLAN, R.E. Differentiating between two Norin 10/Brevor 14 semi-dwarf genes in a common genetic background. Seiken Ziho, 22:83-90, 1970.

ATHWAL, D.S. Semi-dwarf rice and wheat in global food needs. Quarterly Review of Biology, 46:1-34, 1971.

BARCELLOS, A.L. Ferrugem da folha de trigo-população patogênica no Brasil em 1983 e 1984, e reações dos cultivares dos ensaios finais da Região Centro Sul In: REUNIÃO DA COMISSÃO CENTRO-SUL BRASILEIRA DE PESQUISA DE TRIGO, 1., Londrina, 1985. Passo Fundo, Centro Nacional de Pesquisa de Trigo, EMBRAPA, 1985. p.1-38.

BRIGGS, F.N. \& KNOWLES, P.F. Introduction to plant breeding. Davis, Reinhold Publishing Corporation, 1977. $426 \mathrm{p}$.

CAMARGO, C.E.O. \& OLIVEIRA, O.F. Melhoramento do trigo. II - Estudo genético de fontes de nanismo para a cultura do trigo. Bragantia, Campinas, 40:77-91, 1981 .

$\&$ Tolerância de cultivares de trigo a diferentes niveis de alumínio em solução nutritiva e no solo. Bragantia, Campinas, 40:21-31, 1981.

; KRONSTAD, W.E. \& METZGER, R.J. Parent-progeny regression estimates and associations of height level with aluminum toxicity and grain yield in wheat. Crop Science, 20:355-358, 1980. 
COELHO, E.T. Ferrugem do colmo do trigo no Brasil: levantamento de raças em 1980/81 e 1982 (parcial) e teste de resistência dos cultivares dos ensaios norte brasileiros. In: REUNIÃO DA COMISSÃO NORTE-BRASILEIRA DE PESQUISA DE TRIGO, 9., Brasilia, 1983. Passo Fundo, Centro Nacional de Pesquisa de Trigo, EMBRAPA, 1983. p.1-8.

Informações sobre ferrugem do colmo do trigo (Puccinia graminis tritici). In: REUNIÃO DA COMISSÃO CENTRO-SUL BRASILEIRA DE PESQUISA DE TRIGO, 1., Londrina, 1985. Passo Fundo, Centro Nacional de Pesquisa de Trigo, EMBRAPA, 1985. p. 1-5.

HEYNE, E.G. \& CAMPBELL, L.G. Experiments with semi-dwarf wheats in Kansas. Transactions Kansas Academy Science, 74:147-156, 1971.

JOPPA, L.R. Agronomic characteristics of near-isogenic tall and semi-dwarf lines of durum wheat. Crop Science, 13:743-746, 1973.

MEHTA, Y.R. Doenças do trigo e seu controle. São Paulo, Ceres, 1978. 190p.

MOORE, D.P.; KRONSTAD, W.E. \& METZGER, R.J. Screening wheat for aluminum tolerance. In: PROCEEDINGS OF WORKSHOP ON PLANT ADAPTATIONS TO MINERAL STRESS IN PROBLEM SOILS. Beltsville, Maryland, 1976. p.287-295.

OSORIO, E.A. Variedades e melhoramento. In: TRIGO no Brasil. Campinas, Fundação Cargil, 1982. p.147-197.

SCHRAM, W.; FULCO, W.S.; SOARES, M.H.G. \& ALMEIDA, A.M.P. Resistência de cultivares de trigo em experimentação ou cultivo no Rio Grande do Sul às principais doenças fúngicas. Agronomia Sulriograndense, Porto Alegre, 10:31-39, 1974. 